\title{
Is There Any Role for Calcium Ionophore in ICSI Cycles for Cases of Non Obstructive Azoospermia?
}

\author{
Mohamed Elmahdy* ${ }^{(0)}$, Yasser Oreif, Soad Musleh, Emadeldin Khalifa \\ Obstetrics and Gynecology, Alexandria University, Alexandria, Egypt \\ Email: *mahdy_moh@yahoo.com
}

How to cite this paper: Elmahdy, M., Oreif, Y., Musleh, S. and Khalifa, E. (2021) Is There Any Role for Calcium Ionophore in ICSI Cycles for Cases of Non Obstructive Azoospermia? Open Journal of Obstetrics and Gynecology, 11, 1037-1049. https://doi.org/10.4236/ojog.2021.118097

Received: July 9, 2021

Accepted: August 20, 2021

Published: August 23, 2021

Copyright $\odot 2021$ by author(s) and Scientific Research Publishing Inc. This work is licensed under the Creative Commons Attribution International License (CC BY 4.0).

http://creativecommons.org/licenses/by/4.0/

\section{(c) (i) Open Access}

\begin{abstract}
Objectives: Evaluate the effect of artificial oocyte activation (AOA) using calcium ionophore (A23187) on the rate of fertilization and cleavage of embryos in surgically retrieved sperm of patients with non-obstructive azoospermia undergoing intracytoplasmic sperm injection (ICSI). Study design: This study was conducted on 60 infertile couples undergoing ICSI cycles as a randomized controlled parallel group's experimental study in a private IVF center in Egypt from January 2018 to July 2019. ICSI cycles were divided into two groups: Group A: includes 30 ICSI patients with surgically retrieved sperms of non-obstructive azoospermia treated with calcium ionophore (A23187). Group C/Control: includes 30 ICSI patients with surgically retrieved sperms of non-obstructive azoospermia non-treated with calcium ionophore (A23187). Results: There was no statistical difference between both groups regarding the fertilization rate $(p=0.853)$. There was no statistical difference between them regarding implantation rate $(p=0.237)$. The percentage of Class A embryos in the ca ionophore group was $81.7 \%$, while it was $82.8 \%$ in the control group. There was insignificant difference between them $(p=0.782)$. There was no statistical significant difference between the two groups regarding the clinical pregnancy rate, it was (56.7\%) in the ca ionophore group while it was (53.3\%) in the control group. Conclusion: $\mathrm{AOA}$ by $\mathrm{Ca}^{2++}$ ionophore didn't improve the outcome of ICSI cycle in cases of non obstructive azoospermia in terms of fertilization, implantation and pregnancy rate.
\end{abstract}

\section{Keywords}

Fertilization Failure, ICSI, Azosperemia, Ca Ionophore

\section{Introduction}

Fertilization is the process resulting from the fusion of the two parental gametes, 
the oocyte and the sperm. When oocytes and spermatozoa meet in the oviduct, a series of steps are set in motion that leads to fertilization and to the development of a zygote. Fertilization induces a cascade of events that result in the development of the zygote [1].

Fertilization failure after ICSI may occur because of the following conditions. First, the injected oocyte may fail to initiate the biochemical processes necessary for oocyte activation [2]. Second, the biochemical processes are initiated, but they may not occur normally, thus leading to incomplete activation. Third, the sperm can be not accessible for chromatin decondensation and formation of the male pronucleus in the oocyte [3]. Both sperm and oocyte factors are assumed to be involved in failed oocyte activation after ICSI [4] [5]. The Incidence of total fertilization failure (TFF) after ICSI is $1 \%$ - 5\% [6] [7] [8].

Although some suggest no difference [9], the majority of reports show significantly impaired fertilization or pregnancy outcome in cycles using testicular sperm from non obstructive azoospermia (NOA) patients compared with testicular sperm from obstructive azoospermia (OA) patients [10] [11] [12].

Oocyte activation results in the release of the oocyte from its metaphase II (MII) arrested state and leads to further embryo development [13]. It was known that intracellular concentration of calcium $\left(\mathrm{Ca}^{2+}\right)$ levels dramatically change after fertilization [14], which focused attention on the role of this ion [15]. Oocyte activation is characterized by a dramatic rise in intracellular calcium concentration, which in mammals takes the form of calcium oscillations [16] [17], driven by an elevation in inositol triphosphate (IP3) concentrations [18]. The causative agent of these oscillations is proposed to be a recently described phosphoinositide-specific phospholipase $\mathrm{C}$, which is a soluble sperm factor delivered to the egg following membrane fusion [19] [20] [21] [22] [23].

It has been discussed that the calcium oscillation pattern during oocyte activation may influence not only fertilization but also embryo development and therefore the implantation [24] [25]. The most commonly studied AOA model uses the calcium ionophore A23187 [26] [27] [28] [29] [30], to increase the concentration of free $\mathrm{Ca}^{2+}$ in the cytosol, thereby mimicking the physiological cell-signaling mechanism [31].

The aim of this study is to evaluate the effect of artificial oocyte activation (AOA) using calcium ionophore (A23187) on the rate of fertilization and cleavage of embryos in surgically retrieved sperm of patients with non-obstructive azoospermia undergoing intracytoplasmic sperm injection (ICSI).

\section{Materials and Methods}

Study design: randomized controlled.

Study settings: this study was conducted in a private IVF center in Egypt (Repro IVF center) from January 2018 to July 2019.

Sample size: This study was conducted on 60 infertile couples undergoing ICSI cycles as a randomized controlled parallel group's experimental study. ICSI 
cycles were divided into two groups: Group A: includes 30 ICSI patients with surgically retrieved sperms of non-obstructive azoospermia treated with calcium ionophore (A23187). Group C/Control: includes 30 ICSI patients with surgically retrieved sperms of non-obstructive azoospermia non-treated with calcium ionophore (A23187) by closed envelopes methods. Sample size was calculated to include all patients fulfilling the inclusion criteria visiting the center in the study period.

Participants: Inclusion criteria were Couples aged between 20 - 38 years (for the female) with Infertility more than 2 years due to; non-obstructive azoospermic male with normal female. Exclusion criteria: Patient refusal, Poor responders, Endometriosis, Polycystic ovarian syndrome (PCOS), Diabetes and Female with any infertility factor.

Methods: Approval of Ethics Committee in Faculty of Medicine; Alexandria University was taken before conduction of the study. Informed consent was obtained from all participating subjects prior to their inclusion.

All the couples were subjected to the following: full history taking, Hormonal assessment for FSH, LH, AMH, TSH and serum prolactine and Transvaginal ultrasound.

Sperm retrieval was done through microscopic testicular biopsy. The recovered material was examined for the presence of sperms and then was processed by sperm double wash technique.

Ovarian stimulation was through the long agonist protocol. The oocytes were collected after 36 hours from HCG administration. After that, the oocytes were randomly divided into two groups: Experimental group: immediately after injection, the injected oocytes were incubated in culture medium containing $5 \mu \mathrm{mol} / \mathrm{l}$ of the calcium ionophore $\mathrm{A} 23187$ at $37^{\circ} \mathrm{C}$ and $6 \% \mathrm{CO}_{2}$ for $30 \mathrm{~min}$. The oocytes were then washed and incubated in culture medium at $37^{\circ} \mathrm{C}$. After three washing steps, injected eggs will be transferred to microdroplets $(30 \mathrm{ml})$ of sequential culture media until the fertilization check. Control group: after injection, the injected oocytes were subjected to routine ICSI.

Primary outcome: fertilized oocytes and fertilization percentage; around 16 18 hours after ICSI cycle, percent of fertilization will be assessed by the presence of 2 pro nuclei. Secondary outcome: Number of embryos, the percentage of high quality embryos, implantation rate and pregnancy rates.

Embryo transfer was performed on the second or the third or the fifth day of development. High-quality embryos were defined as those having all the following characteristics: either $4-6$ cells on the second day or 8 - 10 cells on the third day of development, less than $10 \%$ fragmentation, symmetric blastomeres, absence of multinucleation, colourless cytoplasm with moderate granulation and no inclusions, absence of perivitelline space granularity, and absence of zona pellucida dysmorphism.

For each couple, one to four embryos were transferred depending on the quality of embryos and the woman age. 


\section{Statistical analysis of the data [32]}

Data were fed to the computer and analyzed using IBM SPSS software package version 21.0. [33] Qualitative data were described using numbers and percentages. Quantitative data were described using range (minimum and maximum), mean, standard deviation and median. Significance of the obtained results was judged at the $5 \%$ level.

The used tests were:

1) Chi-square test

For categorical variables, to compare between different groups.

2) Fisher's Exact or Monte Carlo correction

Correction for chi-square when more than $20 \%$ of the cells have expected count less than 5 .

3) F-test (ANOVA)

For normally quantitative variables, to compare between more than two studied groups, and Post Hoc test (LSD) for pairwise comparisons.

4) Mann Whitney test

For abnormally quantitative variables, to compare between two studied groups.

\section{Results}

There was no statistical significant difference between the two groups regarding male and female age. Male age ranged from 26 years to 65 years with a mean of $39.83 \pm 8.25$ years, and female age ranged from 23 years to 38 years with a mean of $31.74 \pm 4.62$ years in the treated group, while in the control group, male age ranged from 26 years to 58 years with a mean of $37.13 \pm 8.31$ and female age ranged from 18 years to 38 years with a mean of $29.0 \pm 7.83(p=0.212, p=0.143$ consecutively). The total number of mature oocytes in the $\mathrm{Ca}$ ionophore treated group was 373 oocytes, with a mean of $12.43 \pm 5.82$ oocytes, while in control group it was 347 oocytes with a mean of $11.57 \pm 7.65$ oocytes. On comparison between the two groups, there was no statistical significant difference between them $(p=0.332)$. Regarding the fertilized oocytes, the total number in the Ca ionophore treated group was 208 fertilized oocytes, the mean was $6.93 \pm 3.85$ oocytes, while in the control group it was 186 fertilized oocytes with a mean of $6.20 \pm 3.95$ oocytes. On comparison between the two groups, there was insignificant difference between them $(p=0.494)$. The fertilization rate, in the ca ionophore treated group ranged from 20 to 100 with a median of 56.70 , while in control group, it ranged from zero to 100 with a median of 60.66. On comparing between the two groups, there was no statistical difference between them ( $p=$ 0.853) (Table 1). Regarding the implantation rate, in the ca ionophore group it ranged from 25 to 100 with a median of 66.67 , while in the control group, it ranged from 16.76 to 100 with a median of 50.0. On comparison between the two groups, there was no statistical difference between them (Table 1). In the ca ionophore group, the number of embryos was 208 embryos, with a mean of 6.93 \pm 3.85 embryos, while in the control group, it was 186 embryos ranged with a 
Table 1. Comparison between the two studied groups according to fertilization and implantation rate.

\begin{tabular}{ccccc}
\hline & Treated & Control & $\mathrm{U}$ & $p$ \\
\hline Fertilization rate & $(\mathrm{n}=30)$ & $(\mathrm{n}=30)$ & & \\
Min. - Max. & $20.0-100.0$ & $0.0-100.0$ & & \\
Mean \pm SD. & $57.69 \pm 22.77$ & $57.52 \pm 27.01$ & 437.50 & 0.853 \\
Median & 56.70 & 60.66 & & \\
Implantation rate & $(\mathrm{n}=17)$ & $(\mathrm{n}=16)$ & & \\
Min. - Max. & $25.0-100.0$ & $16.67-100.0$ & & \\
Mean \pm SD. & $61.77 \pm 23.58$ & $54.06 \pm 31.99$ & 103.50 & 0.237 \\
Median & 66.67 & 50.0 & & \\
\hline
\end{tabular}

$\mathrm{U}, p$ : $\mathrm{U}$ and $p$ values for Mann Whitney test for comparing between the two groups.

mean of $6.20 \pm 3.95$ embryos. On comparing between the two groups there was no statistical significant difference between them $(p=0.494)$ (Table 2). In the ca ionophore treated group, the number of Class A embryos was 170, with a median of 6 embryos, while in the control group it was 154, with a median of 4 embryos. The percentage of Class A embryos in the ca ionophore group was $81.7 \%$ from total embryos number (208), while it $82.8 \%$ from total embryos number (186). On comparing between the two groups there was insignificant difference between them ( $p=0.494, p=0.782$ consecutively) (Table 2 ). Regarding number of embryos transferred, there was significant difference between the two groups $(p=0.034)$. In the ca ionophore group there was $90(43.3 \%)$ embryos transferred with a mean of $3.0 \pm 1.08$ embryos, while in the control group it was $109(58.6 \%)$ embryos transfered with a mean of $3.63 \pm 1.47$ embryos (Table 2). In the ca ionophore treated group, there was 17 (56.7\%) woman become pregnant and 13 (43.3\%) was non pregnant, while in the control group the women that become pregnant was $16(53.3 \%)$ and 14 (46.7\%) was non pregnant. On comparing between the two groups, there was no statistical significant difference between them (Table 3).

\section{Discussion}

Over the past 20 years, $\mathrm{Ca}$ ionophore have been successfully used in cases of complete globozoospermia [34] [35] [36], or other severe forms of isolated teratozoospermia [37] [38]. Further evidence that male factor infertility is the main indication for $\mathrm{Ca}$ ionophore treatment comes from studies dealing with cryptoor azoospermia [39] [40] [41].

Case reports suggesting the presence of a 50\% previous ICSI fertilization rate threshold below which artificial oocyte activation with an ionophore is likely to improve outcome [28] [42] [43].

There is significant concern because calcium release patterns following ionophore treatment do not mimic those observed during normal fertilization which 
Table 2. Comparison between the two studied groups according to embryo parameters.

\begin{tabular}{ccccc}
\hline & $\begin{array}{c}\text { Treated } \\
(\mathbf{n}=30)\end{array}$ & $\begin{array}{c}\text { Control } \\
(\mathbf{n}=30)\end{array}$ & Test of sig. & $p$ \\
\hline Number of embryos & 208 & 186 & & \\
Min. - Max. & $1.0-15.0$ & $0.0-16.0$ & & \\
Mean \pm SD. & $6.93 \pm 3.85$ & $6.20 \pm 3.95$ & $\mathrm{U}=404.00$ & 0.494 \\
Median & 6.50 & 5.0 & & 0.782 \\
Class A embryos & $170(81.7 \%)$ & $154(82.8 \%)$ & $\chi^{2}=0.076$ & \\
Min. - Max. & $1.0-14.0$ & $0.0-14.0$ & & 0.466 \\
Mean \pm SD. & $5.67 \pm 3.29$ & $5.13 \pm 3.45$ & $\mathrm{U}=401.00$ & \\
Median & 6.0 & 4.0 & & $0.002^{*}$ \\
ferred & $90(43.3 \%)$ & $109(58.6 \%)$ & $\chi^{2}=9.235^{*}$ & \\
Min. - Max. & $1.0-5.0$ & $0.0-6.0$ & & \\
Mean \pm SD. & $3.0 \pm 1.08$ & $3.63 \pm 1.47$ & $\mathrm{U}=310.50^{*}$ & $0.034^{*}$ \\
Median & 3.0 & 4.0 & & \\
\hline
\end{tabular}

$\chi^{2}, p: \chi^{2}$ and $p$ values for Chi square test for comparing between the two groups; $\mathrm{U}, p: \mathrm{U}$ and $p$ values for Mann Whitney test for comparing between the two groups; ${ }^{*}$ : Statistically significant at $p \leq 0.05$.

Table 3. Comparison between the two studied groups according to pregnancy.

\begin{tabular}{ccccccc}
\hline & \multicolumn{2}{c}{$\begin{array}{c}\text { Treated } \\
(\mathrm{n}=30)\end{array}$} & \multicolumn{2}{c}{$\begin{array}{c}\text { Control } \\
(\mathrm{n}=30)\end{array}$} & $\chi^{2}$ & $\boldsymbol{p}$ \\
\cline { 2 - 4 } & No. & $\%$ & No. & $\%$ & & \\
\hline Pregnancy & 13 & 43.3 & 14 & 46.7 & & 0.067 \\
Negative & 17 & 56.7 & 16 & 53.3 & & 0.792 \\
Positive & & & & & & \\
\hline
\end{tabular}

$\chi^{2}, p: \chi^{2}$ and $p$ values for Chi square test for comparing between the two groups.

may affect further development [44]. Although possible risks associated with exposing human oocytes to chemical agents may still be uncovered, calcium ionophore treatment has been widely applied in human oocytes with no evidence of toxicity.

In the present study, fertilization and post fertilzation reproductive outcomes were not significantly improved by its use of ca ionophore. Although the ca ionophore treated group and the control group showed insignificant difference in the number of fertilized oocytes, the treated group was slightly higher than control group in the number of fertilized oocytes $(6.93 \pm 3.85$ vs. $6.20 \pm 3.95)$.

Regarding the fertilization rate and implantation rate, the present study showed insignificant difference between the treated and the control groups, although the fertilization rate was slightly better in the control group, but the implantation rate was better in the treated group. This is in accordance with some difference with the findings of Yoon et al., [45] who demonstrated that Ca io- 
nophore was efficient only in couples with low fertilization $(<50 \%)$ in previous cycles. In their study, a total of 185 ICSI cycles with a history of no or low fertilization was included in retrospective study. They compared outcomes of AOA after ICSI with ejaculated-normal, ejaculated-oligo-astheno-terato or extracted-testicular spermatozoa. They found that, fertilization, cleavage, pregnancy and implantation significantly improved; whereas in couples with fertilization more than $50 \%$, no effect was noted.

The difference that, Yoon et al., [45] compared outcomes of AOA after ICSI with ejaculated-normal, ejaculated-oligo-astheno-terato or extracted-testicular spermatozoa, and their divided into two groups according to fertilization in the previous ICSI cycles (complete fertilization failure and low fertilization groups), while in the present study the patient in both groups was NOA, divided randomly into control and treated groups.

Another largest similar study, [23] including children born on AOA with calcium ionophores, which involved 89 patients, concluded that AOA with calcium ionophores could be efficacious for patients with a fertilization rate that was below $30 \%$ in their previous standard ICSI cycles. However, cases of testis-retrieved spermatozoa were excluded. The present study, by contrast, mainly included patients for whom the spermatozoa was testicular (surgically retrieved sperms), and compared the clinical outcomes.

Hee Jung Kang et al., [46] studied 29 intracytoplasmic sperm injection (ICSI)-AOA cycles involving male factor infertility, Patients were divided into two groups (control, $n=480$; AOA, $n=29$ ). They suggested that, oocyte activation is a useful method to ensure fertilization in TESE-ICSI cycles regardless of restoration of sperm motility after pentoxifylline (PF) treatment and concluded that, ca ionophore did not improve the outcome in TESA ICSI, except in cases with previous fertilization failure and this in agreements with our results.

The difference in their study, they studied male factor infertility, used large number in the control group $(\mathrm{n}=480)$, and they split the treated group into two subgroups according to sperm motility after (PF) treatment, while in the present study, we strict the study on NOA patients, divided randomly into two equal groups ( $\mathrm{n}=30)$ with no PF treatment.

In the present study, calcium ionophore treatment slightly improved ICSI outcomes only in some embryo parametrs, which suggests that not only the spermatozoa but also the oocyte plays a role in oocyte activation. It has been postulated that PLC-z is inactive inside spermatozoa, and that it is activated upon introduction into the oocyte [47]. In addition, it has been postulated that the action of the sperm factor is not a passive process, but instead depends on oocyte agents, such as sperm nucleus decondensation factor (SNDF) [48].

Even though it has been demonstrated that AOA can promote a rise in intracellular calcium concentration, which can result in higher fertilization rates, in the present study, no improvement in fertilization was found when a calcium ionophore was applied. Nevertheless, further embryonic development was found 
to be positively affected by AOA.

The hypothesis that $\mathrm{Ca}^{2++}$ oscillations may provide more than merely a stimulus for meiotic resumption and that they may play a role in long-term embryonic events was previously discussed [49] [50]. It has been shown that differences in $\mathrm{Ca}^{2++}$ signaling patterns can have effects not only on implantation and post-implantation development but also on long-term fetal morphology [50] and weight variation in offspring [25].

The exact mechanism by which intracellular $\mathrm{Ca}^{2++}$ influences embryonic development is not completely understood; however, it has been postulated that the calcium oscillation pattern may partly act through gene expression regulation [50].

In the study by Ebner et al., [51] Ca ionophore treatment during ICSI failed to improve fertilization rates, but instead, it improved the number of embryos going to the blastocyst formation in patients with previous embryo development problems and this is in agreements with the finding of the present study.

Finally, although the findings of this study are interesting, the present trial has some limitations, especially when the groups were done only on non-obstructive azoospermia with surgically retrieved sperms. Therefore, a well-conducted, prospective randomized study with wider types of sever male factors infertility with larger number of patients is needed to give the definitive answers.

\section{Conclusion}

AOA by $\mathrm{Ca}^{2++}$ ionophore didn't improve the outcome of ICSI cycle in cases of non obstructive azoospermia in terms of fertilization, implantation and pregnancy rate.

\section{Declaration}

This study was approved from the Ethics committee, faculty of medicine, Alexandria University. The number is: 0105188.

Written informed consent for publication of their clinical details and/or clinical images was obtained from the patient. A copy of the consent form is available for review by the Editor of this journal.

The datasets used and/or analysed during the current study are available from the corresponding author on reasonable request.

\section{Funds}

Personal.

\section{Authors' Contributions}

ME analyzed and interpreted the patient data regarding the ICSI cycle parameters. EK, YO, SM and ME performed the ovarian stimulation, patients follow-up, ovum pick up and embryo transfer. ME and YO were contributors in writing the manuscript. All authors read and approved the final manuscript. 


\section{Acknowledgements}

Madina and repro IVF centers embryology team for assistance in the work.

\section{Conflicts of Interest}

The authors declare that they have no competing interests.

\section{References}

[1] Shu, Y., Gebhardt, J., Watt, J., Lyon, J., Dasig, D. and Behr, B. (2007) Fertilization, Embryo Development, and Clinical Outcome of Immature Oocytes from Stimulated Intracytoplasmic Sperm Injection Cycles. Fertility and Sterility, 87, 1022-1027. https://doi.org/10.1016/j.fertnstert.2006.08.110

[2] Codreanu, D., Coricovac, A., Mirzan, L., Dracea, L., Marinescu, B. and Boleac, I. (2013) Natural Conception Following Total Fertilization Failure with Intracytoplasmic Sperm Injection in a Couple with Unexplained Infertility: A Case Report. Revista medico-chirurgicala a Societatii de Medici si Naturalisti din Iasi, 117, 431-438.

[3] Mansour, R., Fahmy, I., Tawab, N.A., Kamal, A., El-Demery, Y., Aboulghar, M., et al. (2009) Electrical Activation of Oocytes after Intracytoplasmic Sperm Injection: A Controlled Randomized Study. Fertility and Sterility, 91, 133-139. https://doi.org/10.1016/j.fertnstert.2007.08.017

[4] Eftekhar, M., Mohammadian, F., Yousefnejad, F., Khani, P. and Aflatoonian, A. (2012) Effect of Calcium Ionophore on Unfertilized Oocytes after ICSI Cycles. Iranian Journal of Reproductive Medicine, 10, 83-86.

[5] Kyono, K., Takisawa, T., Nakajo, Y., Doshida, M. and Toya, M. (2012) Birth and Follow-Up of Babies Born Following ICSI with Oocyte Activation Using Strontium Chloride or Calcium Lonophore A23187. Journal of Mammalian Ova Research, 29, 35-40. https://doi.org/10.1274/jmor.29.35

[6] Sousa, M. and Tesarik, J. (1994) Ultrastructural Analysis of Fertilization Failure after Intracytoplasmic Sperm Injection. Human Reproduction, 9, 2374-2380.

https://doi.org/10.1093/oxfordjournals.humrep.a138455

[7] Tejada, M.I., Mendoza, M.R., Corcostegui, B. and Benito, J.A. (1992) Factors Associated with Premature Chromosome Condensation (PCC) Following in Vitro Fertilization. Journal of Assisted Reproduction and Genetics, 9, 61-67. https://doi.org/10.1007/BF01204117

[8] Nasr-Esfahani, M.H., Razavi, S., Mardani, M., Shirazi, R. and Javanmardi, S. (2007) Effects of Failed Oocyte Activation and Sperm Protamine Deficiency on Fertilization Post-ICSI. Reproductive BioMedicine Online, 14, 422-429. https://doi.org/10.1016/S1472-6483(10)60888-7

[9] Windt, M.L., Coetzee, K., Kruger, T.F., Menkveld, R. and van der Merwe, J.P. (2002) Intracytoplasmic Sperm Injection with Testicular Spermatozoa in Men with Azoospermia. Journal of Assisted Reproduction and Genetics, 19, 53-59. https://doi.org/10.1023/A:1014487412975

[10] Palermo, G.D., Schlegel, P.N., Hariprashad, J.J., Ergun, B., Mielnik, A., Zaninovic, N., et al. (1999) Fertilization and Pregnancy Outcome with Intracytoplasmic Sperm Injection for Azoospermic Men. Human Reproduction, 14, 741-748. https://doi.org/10.1093/humrep/14.3.741

[11] Yalcin, I., Berker, B., Sukur, Y.E., Kahraman, K. and Ates, C. (2017) Comparison of Intracytoplasmic Sperm Injection with Testicular Spermatozoa Success in Infertile 
Men with Obstructive and Non-Obstructive Azoospermia: A Retrospective Analysis. Human Fertility (Cambridge, England), 20, 186-191. https://doi.org/10.1080/14647273.2016.1264632

[12] Pasqualotto, F.F., Rossi-Ferragut, L.M., Rocha, C.C., Iaconelli, A. and Borges, E. (2002) Outcome of in Vitro Fertilization and Intracytoplasmic Injection of Epididymal and Testicular Sperm Obtained from Patients with Obstructive and Nonobstructive Azoospermia. The Journal of Urology, 167, 1753-1756.

https://doi.org/10.1016/S0022-5347(05)65193-2

[13] Vanden Meerschaut, F., Leybaert, L., Nikiforaki, D., Qian, C., Heindryckx, B. and De Sutter, P. (2013) Diagnostic and Prognostic Value of Calcium Oscillatory Pattern Analysis for Patients with ICSI Fertilization Failure. Human Reproduction, 28, 87-98. https://doi.org/10.1093/humrep/des368

[14] Machaty, Z. (2016) Signal Transduction in Mammalian Oocytes during Fertilization. Cell and Tissue Research, 363, 169-183. https://doi.org/10.1007/s00441-015-2291-8

[15] Wakai, T., Vanderheyden, V. and Fissore, R.A. (2011) $\mathrm{Ca}^{2+}$ Signaling during Mammalian Fertilization: Requirements, Players, and Adaptations. Cold Spring Harbor Perspectives in Biology, 3, a006767.

[16] Stricker, S.A. (1999) Comparative Biology of Calcium Signaling during Fertilization and Egg Activation in Animals. Developmental Biology, 211, 157-176.

https://doi.org/10.1006/dbio.1999.9340

[17] Hafez, E.S., Goff, L. and Hafez, B. (2004) Mammalian Fertilization, IVF, ICSI: Physiological/Molecular Parameters, Clinical Application. Archives of Andrology, 50, 69-88. https://doi.org/10.1080/aan.50.2.69.88

[18] Rice, A., Parrington, J., Jones, K.T. and Swann, K. (2000) Mammalian Sperm Contain a $\mathrm{Ca}^{2+}$-Sensitive Phospholipase C Activity That Can Generate InsP3 from PIP2 Associated with Intracellular Organelles. Developmental Biology, 228, 125-135. https://doi.org/10.1006/dbio.2000.9929

[19] Saunders, C.M., Swann, K. and Lai, F.A. (2007) PLCzeta, a Sperm-Specific PLC and Its Potential Role in Fertilization. Biochemical Society Symposia, 74, 23-36.

[20] Heytens, E., Schmitt-John, T., Moser, J.M., Jensen, N.M., Soleimani, R., Young, C., et al. (2010) Reduced Fertilization after ICSI and Abnormal Phospholipase C Zeta Presence in Spermatozoa from the Wobbler Mouse. Reproductive BioMedicine Online, 21, 742-749. https://doi.org/10.1016/j.rbmo.2010.07.006

[21] Heytens, E., Soleimani, R., Lierman, S., De Meester, S., Gerris, J., Dhont, M., et al. (2008) Effect of Ionomycin on Oocyte Activation and Embryo Development in Mouse. Reproductive BioMedicine Online, 17, 764-771. https://doi.org/10.1016/S1472-6483(10)60403-8

[22] Tesarik, J., Sousa, M. and Mendoza, C. (1995) Sperm-Induced Calcium Oscillations of Human Oocytes Show Distinct Features in Oocyte Center and Periphery. Molecular Reproduction and Development, 41, 257-263. https://doi.org/10.1002/mrd.1080410217

[23] Montag, M., Koster, M., van der Ven, K., Bohlen, U. and van der Ven, H. (2012) The Benefit of Artificial Oocyte Activation Is Dependent on the Fertilization Rate in a Previous Treatment Cycle. Reproductive BioMedicine Online, 24, 521-526. https://doi.org/10.1016/j.rbmo.2012.02.002

[24] Rout, U.K., Krawetz, S.A. and Armant, D.R. (1997) Ethanol-Induced Intracellular Calcium Mobilization Rapidly Alters Gene Expression in the Mouse Blastocyst. Cell 
Calcium, 22, 463-474. https://doi.org/10.1016/S0143-4160(97)90074-9

[25] Ozil, J.P., Banrezes, B., Toth, S., Pan, H. and Schultz, R.M. (2006) $\mathrm{Ca}^{2+}$ Oscillatory Pattern in Fertilized Mouse Eggs Affects Gene Expression and Development to Term. Developmental Biology, 300, 534-544. https://doi.org/10.1016/j.ydbio.2006.08.041

[26] Dale, B., Fiorentino, A., De Stefano, R., Di Matteo, L., De Simone, M.L., Wilding, M., et al. (1999) Pregnancies after Activated Oocyte Transfer: A New Option for Infertility Treatment. Human Reproduction, 14, 1771-1772.

https://doi.org/10.1093/humrep/14.7.1771

[27] Kim, S.T., Cha, Y.B., Park, J.M. and Gye, M.C. (2001) Successful Pregnancy and Delivery from Frozen-Thawed Embryos after Intracytoplasmic Sperm Injection Using Round-Headed Spermatozoa and Assisted Oocyte Activation in a Globozoospermic Patient with Mosaic Down Syndrome. Fertility and Sterility, 75, 445-447. https://doi.org/10.1016/S0015-0282(00)01698-8

[28] Eldar-Geva, T., Brooks, B., Margalioth, E.J., Zylber-Haran, E., Gal, M. and Silber, S.J. (2003) Successful Pregnancy and Delivery after Calcium Ionophore Oocyte Activation in a Normozoospermic Patient with Previous Repeated Failed Fertilization after Intracytoplasmic Sperm Injection. Fertility and Sterility, 79, 1656-1658.

[29] Murase, Y., Araki, Y., Mizuno, S., Kawaguchi, C., Naito, M., Yoshizawa, M., et al. (2004) Pregnancy Following Chemical Activation of Oocytes in a Couple with Repeated Failure of Fertilization Using ICSI: Case Report. Human Reproduction, 19, 1604-1607. https://doi.org/10.1093/humrep/deh294

[30] Heindryckx, B., Van der Elst, J., De Sutter, P. and Dhont, M. (2005) Treatment Option for Sperm- or Oocyte-Related Fertilization Failure: Assisted Oocyte Activation Following Diagnostic Heterologous ICSI. Human Reproduction, 20, 2237-2241. https://doi.org/10.1093/humrep/dei029

[31] Abramov, A.Y. and Duchen, M.R. (2003) Actions of Ionomycin, 4-BrA23187 and a Novel Electrogenic $\mathrm{Ca}^{2+}$ Ionophore on Mitochondria in Intact Cells. Cell Calcium, 33, 101-112. https://doi.org/10.1016/S0143-4160(02)00203-8

[32] Kotz, S., Balakrishnan, N., Read, B.C. and Vidakovic, B. (2006) Encyclopedia of Statistical Sciences. Wiley-Interscience, Hoboken.

[33] A, K.L. and Feeney, B.C. (2013) A Simple Guide to IBM SPSS Statistics for Version 20.0. Wadsworth, Cengage Learning, Belmont.

[34] Taylor, S.L., Yoon, S.Y., Morshedi, M.S., Lacey, D.R., Jellerette, T., Fissore, R.A., et al. (2010) Complete Globozoospermia Associated with PLCzeta Deficiency Treated with Calcium Ionophore and ICSI Results in Pregnancy. Reproductive BioMedicine Online, 20, 559-564. https://doi.org/10.1016/j.rbmo.2009.12.024

[35] Tejera, A., Molla, M., Muriel, L., Remohi, J., Pellicer, A. and De Pablo, J.L. (2008) Successful Pregnancy and Childbirth after Intracytoplasmic Sperm Injection with Calcium Ionophore Oocyte Activation in a Globozoospermic Patient. Fertility and Sterility, 90, 1202.e1-5.

[36] Kyono, K., Nakajo, Y., Nishinaka, C., Hattori, H., Kyoya, T., Ishikawa, T., et al. (2009) A Birth from the Transfer of a Single Vitrified-Warmed Blastocyst Using Intracytoplasmic Sperm Injection with Calcium Ionophore Oocyte Activation in a Globozoospermic Patient. Fertility and Sterility, 91, 931.e7-11.

[37] Nasr-Esfahani, M.H., Razavi, S., Javdan, Z. and Tavalaee, M. (2008) Artificial Oocyte Activation in Severe Teratozoospermia Undergoing Intracytoplasmic Sperm Injection. Fertility and Sterility, 90, 2231-2237. 
https://doi.org/10.1016/j.fertnstert.2007.10.047

[38] Moaz, M.N., Khattab, S., Foutouh, I.A. and Mohsen, E.A. (2006) Chemical Activation of Oocytes in Different Types of Sperm Abnormalities in Cases of Low or Failed Fertilization after ICSI: A Prospective Pilot Study. Reproductive BioMedicine Online, 13, 791-794. https://doi.org/10.1016/S1472-6483(10)61025-5

[39] Borges, E., de Almeida Ferreira Braga, D.P., de Sousa Bonetti, T.C., Iaconelli, A. and Franco, J.G. (2009) Artificial Oocyte Activation Using Calcium Ionophore in ICSI Cycles with Spermatozoa from Different Sources. Reproductive BioMedicine Online, 18, 45-52. https://doi.org/10.1016/S1472-6483(10)60423-3

[40] Stecher, A., Bach, M., Neyer, A., Vanderzwalmen, P., Zintz, M. and Zech, N.H. (2011) Case Report: Live Birth Following ICSI with Non-Vital Frozen-Thawed Testicular Sperm and Oocyte Activation with Calcium Ionophore. Journal of Assisted Reproduction and Genetics, 28, 411-414. https://doi.org/10.1007/s10815-011-9546-4

[41] Ebner, T., Koster, M., Shebl, O., Moser, M., Van der Ven, H., Tews, G., et al. (2012) Application of a Ready-to-Use Calcium Ionophore Increases Rates of Fertilization and Pregnancy in Severe Male Factor Infertility. Fertility and Sterility, 98, 1432-1437. https://doi.org/10.1016/j.fertnstert.2012.07.1134

[42] Palermo, G., Joris, H., Devroey, P. and Van Steirteghem, A.C. (1992) Pregnancies after Intracytoplasmic Injection of Single Spermatozoon into an Oocyte. The Lancet, 340, 17-18. https://doi.org/10.1016/0140-6736(92)92425-F

[43] Craft, I., Bennett, V. and Nicholson, N. (1993) Fertilising Ability of Testicular Spermatozoa. The Lancet, 342, 864. https://doi.org/10.1016/0140-6736(93)92722-6

[44] Heytens, E., Parrington, J., Coward, K., Young, C., Lambrecht, S., Yoon, S.Y., et al. (2009) Reduced Amounts and Abnormal Forms of Phospholipase C Zeta (PLCzeta) in Spermatozoa from Infertile Men. Human Reproduction, 24, 2417-2428. https://doi.org/10.1093/humrep/dep207

[45] Yoon, H.J., Bae, I.H., Kim, H.J., Jang, J.M., Hur, Y.S., Kim, H.K., et al. (2013) Analysis of Clinical Outcomes with Respect to Spermatozoan Origin after Artificial Oocyte Activation with a Calcium Ionophore. Journal of Assisted Reproduction and Genetics, 30, 1569-1575. https://doi.org/10.1007/s10815-013-0110-2

[46] Kang, H.J., Lee, S.H., Park, Y.S., Lim, C.K., Ko, D.S., Yang, K.M., et al. (2015) Artificial Oocyte Activation in Intracytoplasmic Sperm Injection Cycles Using Testicular Sperm in Human in Vitro Fertilization. Clinical and Experimental Reproductive Medicine, 42, 45-50. https://doi.org/10.5653/cerm.2015.42.2.45

[47] Swann, K., Larman, M.G., Saunders, C.M. and Lai, F.A. (2004) The Cytosolic Sperm Factor That Triggers $\mathrm{Ca}^{2+}$ Oscillations and Egg Activation in Mammals Is a Novel Phospholipase C: PLCzeta. Reproduction, 127, 431-439.

https://doi.org/10.1530/rep.1.00169

[48] Dozortsev, D., Qian, C., Ermilov, A., Rybouchkin, A., De Sutter, P. and Dhont, M. (1997) Sperm-Associated Oocyte-Activating Factor Is Released from the Spermatozoon within 30 Minutes after Injection as a Result of the Sperm-Oocyte Interaction. Human Reproduction, 12, 2792-2796. https://doi.org/10.1093/humrep/12.12.2792

[49] Bos-Mikich, A., Whittingham, D.G. and Jones, K.T. (1997) Meiotic and Mitotic $\mathrm{Ca}^{2+}$ Oscillations Affect Cell Composition in Resulting Blastocysts. Developmental Biology, 182, 172-179. https://doi.org/10.1006/dbio.1996.8468

[50] Ozil, J.P. and Huneau, D. (2001) Activation of Rabbit Oocytes: The Impact of the $\mathrm{Ca}^{2+}$ Signal Regime on Development. Development, 128, 917-928. 
https://doi.org/10.1242/dev.128.6.917

[51] Ebner, T., Oppelt, P., Wober, M., Staples, P., Mayer, R.B., Sonnleitner, U., et al. (2015) Treatment with $\mathrm{Ca}^{2+}$ Ionophore Improves Embryo Development and Outcome in Cases with Previous Developmental Problems: A Prospective Multicenter Study. Human Reproduction, 30, 97-102. https://doi.org/10.1093/humrep/deu285 